\title{
A novel role for vitamin D: modulation of expression and function of the local renin-angiotensin system in mouse pancreatic islets
}

\author{
Q. Cheng • Y. C. Li • B. J. Boucher • P. S. Leung
}

Received: 5 December 2010 /Accepted: 3 February 2011 /Published online: 20 March 2011

(C) Springer-Verlag 2011

\begin{abstract}
Aims/hypothesis The aim of this study was to demonstrate that hormonal vitamin D (calcitriol) modulates the local pancreatic islet renin-angiotensin system (RAS) whilst improving islet beta cell secretory function.

Methods Isolated islets cultured ex vivo under high- or lowglucose conditions and treated with or without calcitriol were examined for changes in RAS component activity and glucose-stimulated insulin secretion (GSIS). Isolated islets from vitamin D receptor knockout (VDR-KO) mice were compared with islets from wild-type (WT) mice for major RAS component expression and RAS protein production.

Results Isolated islets incubated ex vivo under high-glucose conditions showed increased expression and production of major RAS components; this was prevented and reversed by calcitriol in parallel with increases in GSIS. VDR-KO mice displayed increased RAS component mRNA expression and protein production as compared with WT mice, despite comparable glucose homeostasis.
\end{abstract}

Electronic supplementary material The online version of this article (doi:10.1007/s00125-011-2100-1) contains supplementary material, which is available to authorised users.

Q. Cheng $\cdot$ P. S. Leung $(\bowtie)$

School of Biomedical Sciences, Faculty of Medicine,

The Chinese University of Hong Kong,

Shatin, Hong Kong, SAR, People's Republic of China

e-mail: psleung@cuhk.edu.hk

Y. C. Li

Department of Medicine, University of Chicago,

Chicago, IL, USA

B. J. Boucher

Centre for Diabetes, Bart's and The London School of Medicine and Dentistry, Queen Mary, University of London,

London, UK
Conclusions Young mice with vitamin D receptor ablation showed abnormal increases in islet RAS components at mRNA and protein levels, despite unaltered glucose homeostasis. Calcitriol prevents and can correct induction of RAS component production under high-glucose conditions in parallel with the well-known effect of calcitriol on increasing islet beta cell secretory responses to glucose.

Keywords Angiotensin II · Calcitriol · Hyperglycaemia · Insulin secretion · Pancreatic islets · Type 2 diabetes . Vitamin D receptor

$\begin{array}{ll}\text { Abbreviations } \\ \mathrm{AT}_{1} \text { receptor } & \text { Angiotensin II type 1 receptor } \\ \text { GSIS } & \text { Glucose-stimulated insulin secretion } \\ \text { 25(OH)D } & \text { 25-Hydroxycholecalciferol } \\ \text { IPGTT } & \text { Intra-peritoneal glucose tolerance test } \\ \text { RAS } & \text { Renin-angiotensin system } \\ \text { VDR } & \text { Vitamin D receptor } \\ \text { VDR-KO } & \text { Vdr-knockout } \\ \text { WT } & \text { Wild-type }\end{array}$

\section{Introduction}

Convergent data have demonstrated functional reninangiotensin systems (RASs) locally in many tissues and organs, with various physiological roles. Concurrently, we have demonstrated local RAS expression in pancreatic islets, which varies with glycaemic control [1] and is excessively expressed in a mouse model of type 2 diabetes [2]; angiotensin II type 1 receptor $\left(\mathrm{AT}_{1}\right.$ receptor) blockade improves islet function and glucose tolerance in hyperglycaemia [2]. Hyperglycaemia may be worsened through $\mathrm{AT}_{1}$ receptor-induced uncoupling protein 2-driven oxidative 
stress, reducing islet beta cell mass and insulin secretion [3]. The combination of $\mathrm{AT}_{1}$ receptor blockers with other glucose-lowering agents has a synergistic effect in reducing type 2 diabetes risks [4], further indicating a critical role for the RAS in modulating pancreatic islet function.

Calcitriol-bound vitamin D receptors (VDRs) in human and rodent pancreatic islets have physiological roles in islet function, including insulin secretion. Clinical studies indicate relationships between vitamin D status, glycaemia and type 2 diabetes risks [5]; animal studies show decreased insulin secretory capacity and glycaemic control in vitamin D deficiency and in $V d r$ knockout (VDR-KO) mice [6]. Several clinical studies demonstrate inverse relationships between circulating 25 -hydroxycholecalciferol $\left[25(\mathrm{OH}) \mathrm{D}_{3}\right]$ and renin activity in hypertensive patients and with myocardial dysfunction, supported by animal VDR-KO data [6]. Vitamin D suppresses renin production, the rate-limiting enzyme in RAS activity [7]. We now report that activated hormonal vitamin D (calcitriol) suppresses expression and production of islet RAS components in isolated mouse pancreatic islets.

\section{Methods}

Animals Adult male C57BL/6J mice were obtained from the Laboratory Animal Services Centre of the Chinese University of Hong Kong with approval from the Animal Experimentation Ethics Committee of the Chinese University of Hong Kong (Ref. no. 08/049/ERG). Eight-week-old male VDR-KO mice and WT littermates were used as described previously [7] with ethical approval from the Institutional Animal Care and Use Committee at the University of Chicago.

Pancreatic islet isolation, primary culture and calcitriol pre-treatment As described previously [8], pancreatic islets isolated from adult $\mathrm{C} 57 \mathrm{BL} / 6 \mathrm{~J}$ mice using intra-ductal collagenase injection methodology were cultured in medium containing different concentrations of glucose together with calcitriol (Alexi, Lausen, Switzerland) for 7 days.

Detection of $m R N A$ and protein levels Isolated islets were processed for mRNA detection by conventional PCR and real-time quantitative PCR as described previously [4] using primer sequences listed in electronic supplementary material (ESM) Table 1, for western blotting after each experiment and islet beta cell immunofluorescence staining as previously described [3,9] using antibodies listed in ESM Table 2.

Measurement of glucose homeostasis, glucose-stimulated insulin secretion (GSIS) and (pro)insulin biosynthesis Blood glucose concentrations and glucose tolerance were assessed as previously described [2]. Ten size-matched isolated islets from each experimental treatment group were used for measurement of GSIS and (pro)insulin biosynthesis as described previously $[3,8]$.

Statistics Results are expressed as means \pm SEM. Data were analysed by two-tailed Student's $t$ test, or one-way ANOVA, followed by Tukey's post hoc test.

\section{Results}

Effects of calcitriol on RAS component expression in isolated islets under high-glucose conditions Isolated islets were incubated under different glucose conditions together with or without continuous treatment with calcitriol (pretreatment). Renin receptor and $\mathrm{AT}_{1}$ receptor mRNA expression was clearly increased by incubation with $28 \mathrm{mmol} / 1$ glucose, while there were non-significant changes in angiotensinogen mRNA expression. Pretreatment with $1 \times 10^{-9}$ or $1 \times 10^{-8} \mathrm{~mol} / 1$ calcitriol prevented these increases although it did not induce significant changes in angiotensinogen expression (Fig. 1a-c). Inhibitory effects of calcitriol were also observed when calcitriol was added with high- but not low-glucose exposure, for renin, renin receptor and $\mathrm{AT}_{1}$ receptor protein production (Fig. 1d-f). $V d r$ expression and VDR protein levels, shown in the islet beta cells (ESM Fig. 1a), increased with calcitriol treatment under both 28 and $5.6 \mathrm{mmol} / 1$ glucose conditions (ESM Fig. $1 \mathrm{~b}-\mathrm{e}$ ). $1 \times 10^{-9} \mathrm{~mol} / \mathrm{l}$ calcitriol had no effects on RAS component mRNA or protein values in islets exposed to $5.6 \mathrm{mmol} / \mathrm{l}$ glucose (Fig. 1a-f). Posttreatment studies, where islets were treated with calcitriol after a 2 day $28 \mathrm{mmol} / 1$ glucose incubation, showed that the addition of calcitriol reversed high-glucose activation of RAS component expression and production to near normal levels, optimally, at $1 \times 10^{-9} \mathrm{~mol} / \mathrm{l}$ (ESM Fig. $2 \mathrm{a}-\mathrm{f}$ ).

Effects of calcitriol on GSIS under high-glucose stress in isolated islets Ten islets from each study group were incubated with $1.7 \mathrm{mmol} / \mathrm{l}$ glucose before challenge with $16.7 \mathrm{mmol} / 1$ glucose. Pre-treatment with $1 \times 10^{-9} \mathrm{~mol} / 1$ calcitriol (Fig. 1g) significantly improved glucose challenge-induced insulin secretion and similar effects were observed in high-glucose incubated islets after post-treatment with calcitriol (ESM Fig. 2g, h).

Glucose homeostasis and islet expression of major RAS components in VDR-KO mice VDR-KO mice had significantly lower body weights than their WT littermates at 8 weeks old (Fig. 2a). However, both fasting and random blood glucose concentrations in VDR-KO mice were indistinguishable from those of WT mice (Fig. 2b,c), as 
Fig. 1 The protective effect of pre-treatment of isolated islets with various concentrations of calcitriol for prevention of high-glucose-induced increases in RAS component expression and production, as well as induction of insulin secretion. Angiotensinogen (a), renin receptor $(\mathbf{b})$ and $\mathrm{AT}_{1}$ receptor $(\mathbf{c})$ mRNA expression were measured in isolated islets pre-treated with calcitriol together with high or low concentrations of glucose (pre-treatment). These were assessed, together with protein production of renin (d), renin receptor $(\mathbf{e})$ and $\mathrm{AT}_{1}$ receptor (f), $\left({ }^{*} p<0.05, * * p<0.01\right.$, $* * * p<0.001$ vs $28 \mathrm{mmol} / 1$ glucose + vehicle; $n=6$ ). g Isolated islets incubated at $28 \mathrm{mmol} / \mathrm{l}$ glucose from experiments shown in $(\mathbf{d}-\mathbf{f})$ were examined for GSIS at both $1.7 \mathrm{mmol} / 1$ (white bar) and $16.7 \mathrm{mmol} / \mathrm{l}$ (grey bar) glucose, with/without added calcitriol $\left({ }^{*} p<0.05\right.$ vs $28 \mathrm{mmol} / \mathrm{l}$ glucose + vehicle; $n=7$ ) a

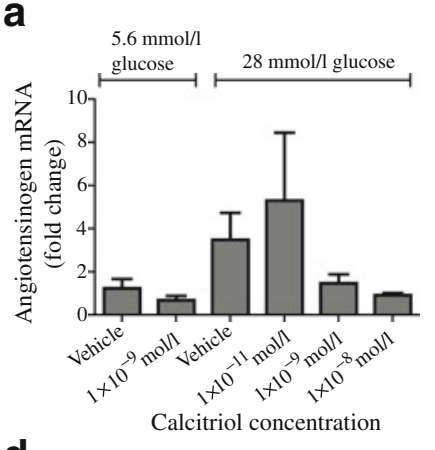

d

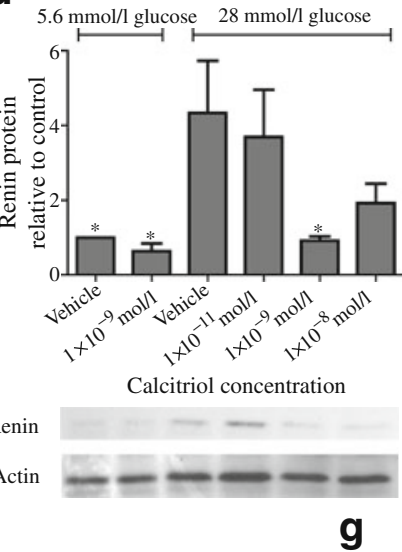

g b

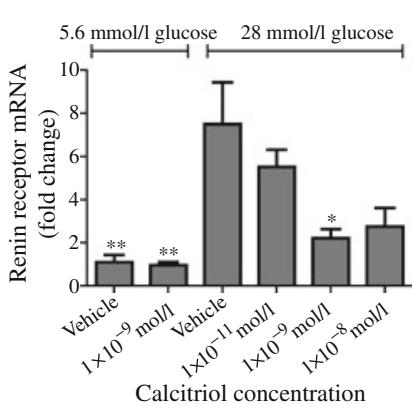

e

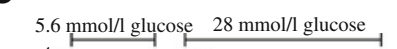

C

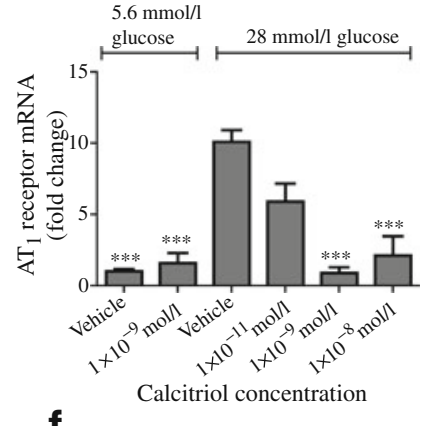

f
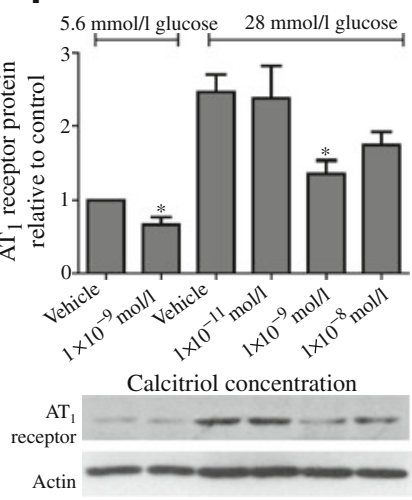

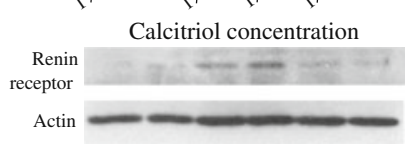

Actin

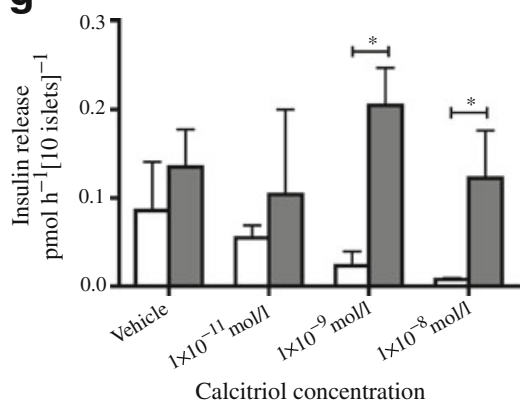

reported previously [7]. Changes in glucose tolerance over time (IPGTT), expressed as AUC, did not differ between VDR-KO and WT mice (Fig. 2d,e). VDR-KO mouse islets exhibited increases in mRNA expression of, in particular, the renin receptor and $\mathrm{AT}_{1}$ receptor $(\mathrm{Fig} .2 \mathrm{f}-\mathrm{h})$ while renin protein was consistently and markedly increased in VDRKO mouse islets (Fig. 2i).

\section{Discussion}

In the present study, we demonstrate, for the first time to our knowledge, that vitamin D modulates islet RAS components, identifying an additional mechanism for the beneficial effects of vitamin D on pancreatic islet beta cell function. The ablation of vitamin D effects in VDR-KO mice was associated with increased islet RAS component expression, independent of glucose concentration. High-glucose-induced increases in RAS components and GSIS were both protected, to various degrees, by prior exposure to physiological concentrations of hormonal vitamin D (calcitriol).

Various previous studies have suggested non-calcaemic roles of vitamin $\mathrm{D}$, including beneficial effects on blood pressure, cardiovascular disease and diabetes risk, and elevated renin levels are reported in VDR-KO mouse kidney [7]. To determine the interaction of vitamin D with the islet RAS, we employed global VDR-KO mice, known to have elevated circulating renin and angiotensin II levels, as well as other local RAS components including renin [7]. However, glucose homeostasis in 8-week-old VDR-ablated mice was not abnormal, perhaps related to their smaller body size and other indirect effects of VDR-KO, although their islet size and structure were unchanged (Q. Cheng and P.S. Leung, unpublished data). Thus, changes in the islet RAS in 8-week-old mice appear to arise, not due to high glucose exposure but due to lack of ligand-bound VDRinduced suppression, since the changes are present even without hyperglycaemia. Therefore, physiologically, the 

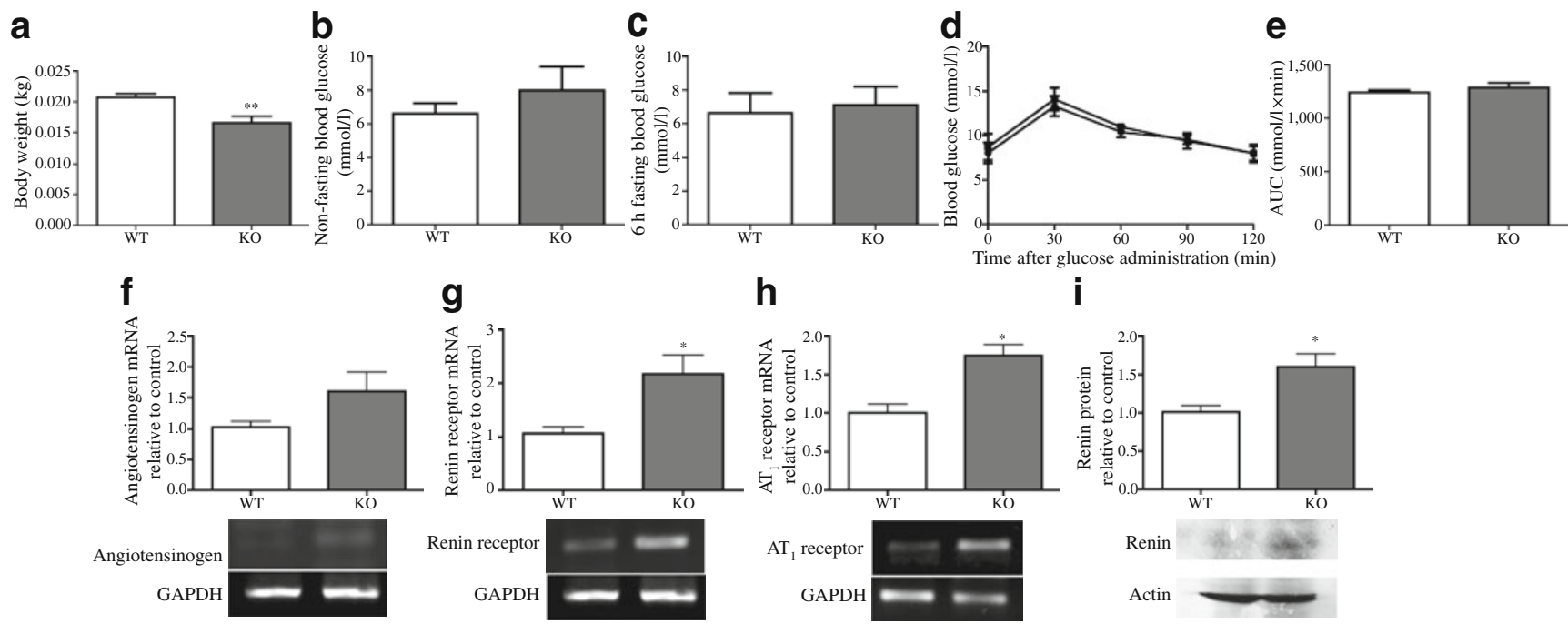

h

i

Fig. 2 Body weight, glucose homeostasis and pancreatic islet RAS component expression of VDR-KO mice and WT mice. (a), Body weight and (b), non-fasting and (c), fasting blood glucose concentrations were examined in 8-week-old VDR-KO and WT mice. IPGTT was measured using standard IPGTTs and glucose profile calculated
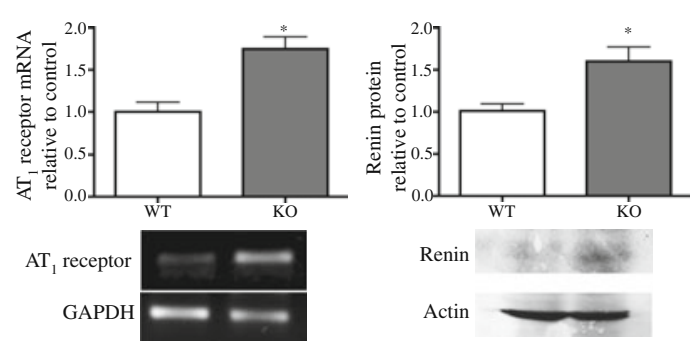

as AUC (d, e). Major islet RAS component mRNA expression was measured by conventional PCR and semi-quantitative PCR (f-h), and renin protein production was assessed by western blot (i) $\left({ }^{*} p<0.05\right.$, $* * p<0.01$ vs WT, $n=5$ )

glucose level. The increases in RAS component formation induced by high glucose concentrations in isolated mouse islets can be prevented by calcitriol, with concomitant increases in islet insulin secretion. Our findings, therefore, suggest protective effects of better vitamin D status against abnormal increases in islet RAS activity, especially in hyperglycaemia. These effects have the potential to contribute to islet beta cell protection and to reduction in type 2 diabetes risk, in addition to the well-known direct effects of calcitriol on insulin secretion. Further investigations are required to confirm a direct relationship between vitamin $\mathrm{D}$ and islet RAS, to determine the mechanisms by which vitamin D modulates islet RAS activity, to establish how increased RAS activity induces beta cell dysfunction in mice and in humans, and to determine whether RAS blockers and adequate provision of vitamin $\mathrm{D}$ can work synergistically for the reduction in type 2 diabetes risks.

Acknowledgements This work was supported by the General Research Fund from Research Grants Council of Hong Kong (Project No. 470709) and the Focused Investment Scheme C from the Chinese University of Hong Kong (Ref. No. 1903016), awarded to P.S. Leung.

Duality of interest The authors declare that there is no duality of interest associated with this manuscript.

\section{References}

1. Lau T, Carlsson PO, Leung PS (2004) Evidence for a local angiotensin-generating system and dose-dependent inhibition of glucose-stimulated insulin release by angiotensin II in isolated pancreatic islets. Diabetologia 47:240-248 
2. Chu KY, Lau T, Carlsson PO, Leung PS (2006) Angiotensin II type 1 receptor blockade improves beta-cell function and glucose tolerance in a mouse model of type 2 diabetes. Diabetes 55:367-374

3. Chu KY, Leung PS (2007) Angiotensin II type 1 receptor antagonism mediates uncoupling protein 2-driven oxidative stress and ameliorates pancreatic islet beta-cell function in young type 2 diabetic mice. Antioxid Redox Signal 9:869-878

4. Cheng Q, Law PK, de Gasparo M, Leung PS (2008) Combination of the dipeptidyl peptidase IV inhibitor LAF237 [(S)-1-[(3hydroxy-1-adamantyl)ammo]acetyl-2-cyanopyrrolidine] with the angiotensin II type 1 receptor antagonist valsartan $[N-(1-$ oxopentyl)- $N$-[[2'-(1 H-tetrazol-5-yl)-[1,1'-biphenyl]-4-yl]methyl]-L-valine] enhances pancreatic islet morphology and function in a mouse model of type 2 diabetes. J Pharmacol Exp Ther 327:683691

5. Boucher BJ (2011) Vitamin D insufficiency and diabetes risks. Curr Drug Targets 12:61-87
6. Goltzman D (2010) Vitamin D action: lessons learned from genetic mouse models. Ann NY Acad Sci 1192:145-152

7. Li YC, Kong J, Wei M, Chen ZF, Liu SQ, Cao LP (2002) 1, 25 Dihydroxyvitamin $\mathrm{D}(3)$ is a negative endocrine regulator of the renin-angiotensin system. J Clin Invest 110:229-238

8. Chu KY, Cheng Q, Chen C et al (2010) Angiotensin II exerts glucose-dependent effects on $\mathrm{Kv}$ currents in mouse pancreatic beta-cells via angiotensin II type 2 receptors. Am J Physiol Cell Physiol 298:C313-C323

9. Wong KE, Szeto FL, Zhang W et al (2009) Involvement of the vitamin D receptor in energy metabolism: regulation of uncoupling proteins. Am J Physiol Endocrinol Metab 296:E820-E828

10. Forouhi NG, Luan J, Cooper A, Boucher BJ, Wareham NJ (2008) Baseline serum 25-hydroxy vitamin $\mathrm{D}$ is predictive of future glycemic status and insulin resistance: the Medical Research Council Ely Prospective Study 1990-2000. Diabetes 57:26192625 